\title{
Anti-tumor Activity of Paclitaxel Prodrug Conjugated with Polyethylene Glycol
}

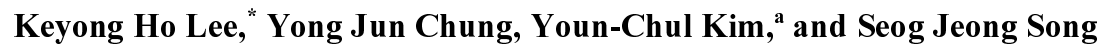 \\ Kolon Central Research Park, Yongin, Kyunggi-Do 449-797, Korea. *E-mail: khlee67@kolon.com \\ Received February 18, 2005
}

\begin{abstract}
The purpose of this study was to develop a method for increasing the solubility of paclitaxel in water to reduce its toxicity and make the drug more feasible for chemotherapy. A series of highly water soluble paclitaxel polyethylene glycol (PEG) esters were synthesized and evaluated for their anti-tumor activity and toxicity. The solubility of 7-polyethylene glycol paclitaxel carbonate 5 was $840 \mathrm{mg} / \mathrm{mL}$ and the acute toxicity $\left(\mathrm{LD}_{50}\right)$ was $286 \mathrm{mg} / \mathrm{kg}$. Because of its reduced toxicity, compound 5 showed a dramatic reduction of tumor volume without any loss of animals in long-term treatment (daily consecutive injections for 15 days).
\end{abstract}

Key Words : Paclitaxel, 7-Polyethylene glycol paclitaxel carbonate, Anti-tumor activity, Toxicity, Watersolubility

\section{Introduction}

It is well known that the use of anti-cancer agents in cancer therapy causes a large number of toxic side effects that may be life-threatening for the patients. These complications may require a reduction in the doses of the chemotherapeutic agents, and occasionally interruption of therapy itself.

Thus, the discovery of new effective agents with reduced toxicity is clinically important. Taxol is a natural extract, first isolated from the bark of Taxus breuifolia, with anticancer properties but the agent has neurotoxic and myelotoxic side effects in human. The drug is used for treating tumors resistant to platinum therapy, but it causes cumulative toxicity in the peripheral nervous system. ${ }^{1,2}$

Paclitaxel is taxol for injection formulated as Cremophor EL (polyoxyethylated castor oil and ethyl alcohol (50\% $\mathrm{v} / \mathrm{v})$ ) to improve the solubility of taxol. The problem associated with very poor water solubility has been a major hindrance to the development of paclitaxel in clinical trials. ${ }^{3-5}$ Currently, paclitaxel $\mathbf{1}$ is formulated as a concentrated solution containing $6 \mathrm{mg} / \mathrm{mL}$ in Cremophor EL. However, it became evident that the Cremophore EL as a surfactant causes serious side effects such as hypersensitivity reactions in some patients. In addition, vegetable oils such as Cremophor EL are used in parenteral fluids. Moreover, the use of alcohol as organic solvents causes problems such as hemolysis at injection area and local irritation. ${ }^{6-10}$ To ensure safer drug delivery to patients, watersoluble paclitaxel prodrugs are necessary for the preparation and administration of paclitaxel solutions.

To develop highly water-soluble and less toxic paclitaxel analogues, we designed and synthesized new prodrug of paclitaxel, 7-polyethylene glycol (PEG) paclitaxel carbonate 5.

In this paper, we report on a simple synthetic route for the preparation of the carbonate $\mathbf{5}$, and evaluate its anti-tumor activity and toxicity.

${ }^{a}$ Present addresss: Pharm \& Specialty Chemicals Inc., Chungbuk 369823 , Korea

\section{Material and Methods}

Synthesis. A synthetic route for prodrug of paclitaxel, 7polyethylene glycol (PEG) paclitaxel carbonate 5, is outlined in Scheme 1. Briefly, paclitaxel 1 was protected with tert-butyldimethylsily group in anhydrous methylene chloride to obtain 2'-tert-butyldimethylsilyl protected paclitaxel 2. 2'tert-Butyldimethylsilyl-7-chloromethyloxycarbonyl-paclitaxel 3 was prepared by treating 2 with chloromethylchloroformate and pyridine in anhydrous methylene chloride. Desilylation of compound 3 with $2 \%$ HF produced compound 4. And then, PEGylation of compound 4 with PEGsuccinate produced 7-mPEG-succinyloxymethyloxycarbonylpaclitaxel (7-polyethylene glycol paclitaxel carbonate 5).

Water solubility. Estimation of paclitaxel percentage in the prodrug was determined by Li's method. ${ }^{4}$

Water solubility was estimated by dissolving appropriate amounts of prodrug in $0.1 \mathrm{~mL}$ water. The UV spectrum of the prodrug in water was obtained and the absorbance at 288 nm was used to quantify the concentration of paclitaxel in the prodrug. A paclitaxel standard series prepared in methanol was used to generate a calibration curve, assuming the prodrug and paclitaxel have the same absorption coefficient.

Tumor cell culture. The human mammary tumor cell line MX-1, the human cervix tumor cell line HeLa and the animal tumor cell line B16F10 were purchased from the American Type Culture Collection (Rockville, MD). MX-1 was maintained in RPMI 1640 (Gibco BRL, Grand Island NY, USA) supplemented with $10 \%$ heat-inactivated fetal bovine serum (Gibco BRL, Grand Island NY, USA) B16F10 was maintained in minimum essential medium (Gibco BRL, Grand Island NY, USA) supplemented with 10\% heatinactivated fetal bovine serum (Gibco BRL, Grand Island NY, USA).

Anti-tumor activity. Blab/c $n u / n u$ mice (SLC, Japan) were provided and maintained on UV sterilized tap water and lab chow (Samyang, Korea) and were housed at $23{ }^{\circ} \mathrm{C}$, $55 \pm 10 \%$ humidity, in a $12 \mathrm{~h}$ light/dark cycle. 


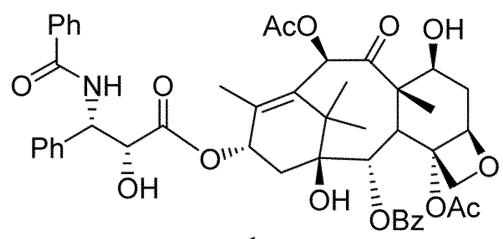
1

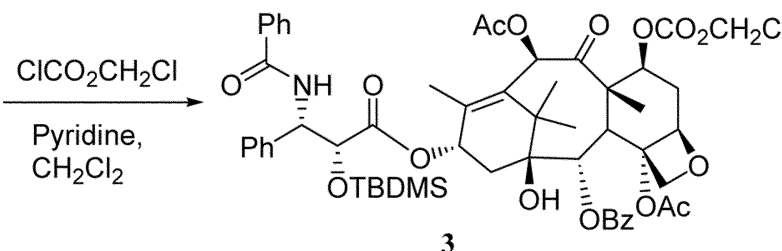
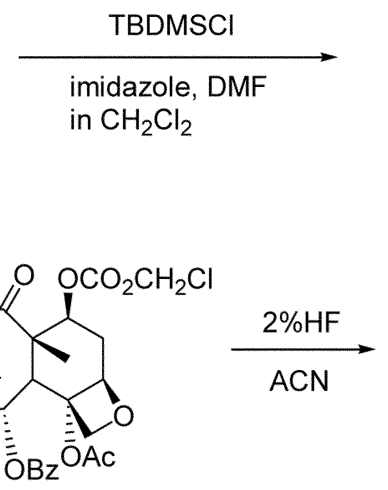

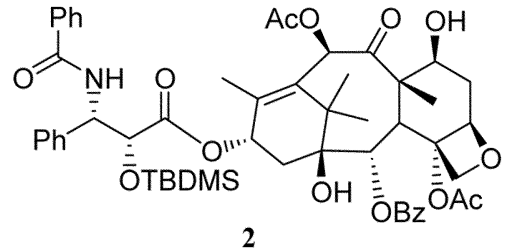

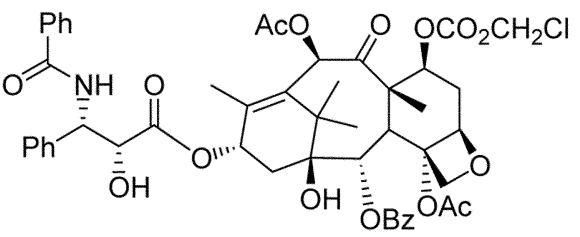

4
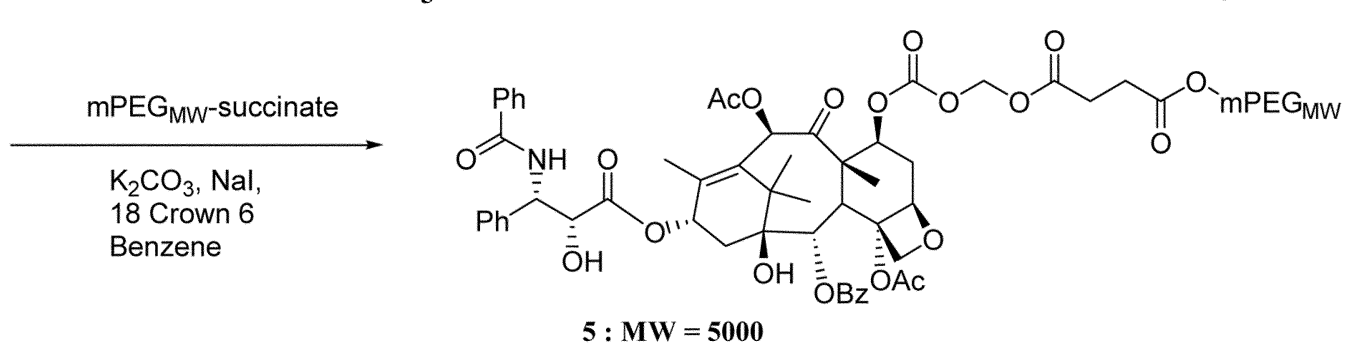

Scheme 1. Reagent and conditions: (a) TBDMSCl/imidazole $/ \mathrm{CH}_{2} \mathrm{Cl}_{2}, \mathrm{rt}, 99 \%$; (b) pyridine $/ \mathrm{ClCO}_{2} \mathrm{CH}_{2} \mathrm{Cl} / \mathrm{CH}_{2} \mathrm{Cl}_{2}, 0{ }^{\circ} \mathrm{C}$ to $\mathrm{rt}, 88.1 \%$; (c) $2 \%$ $\mathrm{HF} / \mathrm{CH}_{3} \mathrm{CN}, \mathrm{rt}, \geq 99 \%$; (d) $\mathrm{mPEG}_{\mathrm{MW}}$-succinate $/ \mathrm{NaI} / \mathrm{K}_{2} \mathrm{CO}_{3} / 18$-Crown-6/Benzene, reflux, $68 \%$.

Thirty to forty $\mathrm{mg}$ tumor fragments were implanted subcutaneously into mice using 12 gauge trocar needles. Groups of 10 randomly assigned athymic mice (Blab/c $n u /$ $n u, 6$ weeks male) bearing HeLa (human cervix tumor cell line) and MX-1 (human mammary tumor cell line) were treated intravenously (iv) with paclitaxel and compound $\mathbf{5}$ when the median tumor volume increased 200 to 400 $\mathrm{mm}^{3} .^{11,12}$ The dose of compound 5 was $12 \mathrm{mg} / \mathrm{kg}$ and $16 \mathrm{mg} /$ $\mathrm{kg}$ as based on paclitaxel dose. Tumor volume was determined by caliper measurement $(\mathrm{mm})$ and using the formula for an ellipsoid sphere: $\mathrm{LW}^{2} / 2=\mathrm{mm}^{3}$, when L (length) and $\mathrm{W}$ (width) are in mm.

Anti-metastasis. Lung metastasis of B16F10 melanoma cells were assessed by iv inoculation of tumor cells in C57BL/6 (6 weeks old male) on day 0. Paclitaxel and compound 5 treatments were administered iv, once daily for 10 days starting on Day -2 (i.e. Day -2 to Day 7). On day 14 after tumor cell injection, all the mice were killed. Lungs were excised and fixed in Bouin's solution and tumor colonies were enumerated. ${ }^{13}$

Toxicity. Acute lethality was performed in non-tumor bearing female and male ICR mice 6-7 weeks old. Mice were monitored for survival up to 14 days. ${ }^{14}$ Paclitaxel was suspended in ethanol: Cremophor EL: water, and compound 5 was solubilized in sterile PBS immediately before injection. Toxicity was examined using $\mathrm{LD}_{50}$ values.

\section{Results and Discussion}

In general, water-soluble paclitaxel prodrugs have been prepared by introducing ionic moieties to paclitaxel either at C2' or C7 hydroxyl groups. ${ }^{4,15,16}$ Greenwald et al. reported 2'-poly(ethylene glycol) ester prodrugs, which have various PEG molecular sizes ranging from $5 \mathrm{KDa}$ to $40 \mathrm{KDa}$. In the current studies, we have synthesized new PEG-conjugated paclitaxel prodrugs with PEG molecules weights of 5,000 and 20,000 and then evaluated their anti-tumor activity. We found that there was a difference in anti-tumor activity related to the change of PEG molecular size. 7-Paclitaxel carbonate conjugated with 20,000 molecular weight PEG showed a lower activity than that conjugated with 5,000 molecular weight PEG. The half-life of prodrug conjugated with 5,000 molecular weight PEG for hydrolysis in fresh human plasma was 2 min. In addition, this prodrug was converted to paclitaxel in $<10 \mathrm{~min}$ when incubated at $37^{\circ} \mathrm{C}$ with human plasma. In contrast, the half-life of prodrug conjugated with 20,000 molecular weight PEG for hydrolysis was longer than that of the 5,000 PEG conjugate. This result is different from that reported by several researchers. ${ }^{17-19}$ According to the results of many researchers, the high molecular weight PEG prodrug conjugates, such as paclitaxel carbonate conjugated with 20,000 molecular weight PEG, produce an improved therapeutic effect that may arise from two distinct features. Firstly, the transport of the high molecular forms may be associated with a longer circulatory half-life. Secondly, the high-molecular weight polymer-drug conjugate would be expected to selectively accumulate in the tumor. Unfortunately, we could not obtain the results that support these proposals. We synthesized the 7-polyethylene glycol paclitaxel carbonate 5 conjugated with 5,000 molecular weight PEG. The differences between paclitaxel and the compound $\mathbf{5}$ were analyzed using ${ }^{1} \mathrm{H}$ NMR. We were able to find the peaks of PEG-conjugate, that is, $\left.1 \mathrm{H} \mathrm{NMR} \mathrm{(300} \mathrm{MHz,} \mathrm{CDCl}_{3}\right): 4.39-3.38$ ( $\left.m, \mathrm{mPEG}\right)$, 
Table 1. Aqueous solubility of 5

\begin{tabular}{ccc}
\hline Prodrug & Solubility $(\mathrm{mg} / \mathrm{mL})$ & Conc. of paclitaxel $(\mathrm{mg} / \mathrm{mL})$ \\
\hline $\mathbf{5}$ & 840 & 120 \\
\hline
\end{tabular}

$5.88\left(d, 1 \mathrm{H}, J=5.85 \mathrm{~Hz}, \mathrm{CCOOCH}_{2} \mathrm{O}\right), 5.71(d, 1 \mathrm{H}, J=$ $\left.5.85 \mathrm{~Hz}, \mathrm{CCOOCH}_{2} \mathrm{O}\right)$.

The maximum solubility of compound 5 was $840 \mathrm{mg} / \mathrm{mL}$, which corresponded to the solubility of paclitaxel $120 \mathrm{mg} /$ $\mathrm{mL}$ (Table 1). When $400 \mathrm{mg}$ of compound 5 was dissolved in $1 \mathrm{~mL}$ of water, a clear, viscous yet flowable liquid was obtained. Li et al. reported the solubility of 2'-PEGpaclitaxel was at least $200 \mathrm{mg} / \mathrm{mL}$, and Greenwald et al. reported the solubility of 2'-PEG-paclitaxel was $660 \mathrm{mg} / \mathrm{mL}$. The solubility of compound $\mathbf{5}$ was better than the prodrug of $\mathrm{Li}$ or Greenwald's, and the synthesis of compound $\mathbf{5}$, of which PEG was introduced at position $\mathrm{C} 7$ of paclitaxel, was easier than 2'-PEG-paclitaxel. The acute toxicity $\left(\mathrm{LD}_{50}\right)$ of compound $\mathbf{5}$ administered by intravenous injection was 286 $\mathrm{mg} / \mathrm{kg}$ for a single dose in mice. The toxicity value for a single dose is low compared to $25 \mathrm{mg} / \mathrm{kg}$ of paclitaxel.

To establish the anti-tumor activity of compound $\mathbf{5}$ against human tumor in vivo, Balb/c mice bearing transported HeLa and MX-1 tumors were treated with paclitaxel or compound 5 at the same dose of $12 \mathrm{mg} / \mathrm{kg}$ based on paclitaxel dose. Compound 5 exhibited a lower anti-tumor effect than $12 \mathrm{mg} /$ $\mathrm{kg}$ paclitaxel during a cause of 5 days consecutive injection (data not shown). Despite these results, we tried to examine the effect by longer-term injections (daily consecutive injection for 15 days), because compound $\mathbf{5}$ had a lower toxicity than paclitaxel as judged by its $\mathrm{LD}_{50}$ value.

In Figure 1, the treatment with compound 5 at the two doses showed a tumor inhibitory effect of $90 \%$ or more on the growth of transplanted HeLa and MX-1 tumor cells. The treatment using $12 \mathrm{mg} / \mathrm{kg}$ or $16 \mathrm{mg} / \mathrm{kg}$, which presents a concentration six to eight times higher than $2 \mathrm{mg} / \mathrm{kg}$ of paclitaxel, produced significant reductions in tumor weight. In the group treated with $16 \mathrm{mg} / \mathrm{kg}$, tumor growths of both cell lines regressed totally in most of the mice. In the group treated with $12 \mathrm{mg} / \mathrm{kg}$, a slight delay in tumor growth was obtained only with the MX-1 cell line. However the overall effect of long-term injections at the two doses was significantly higher than that of short-term injection (daily for 5 days) and $12 \mathrm{mg} / \mathrm{kg}$ of paclitaxel (Data not shown). We did not find weight reduction in mice treated with $12 \mathrm{mg} / \mathrm{kg}$ or $16 \mathrm{mg} / \mathrm{kg}$ of compound $\mathbf{5}$, but detected a slight weight reduction in the treatment with $2 \mathrm{mg} / \mathrm{kg}$ of paclitaxel. In the mice having long-term treatment with $12 \mathrm{mg} / \mathrm{kg}$ of paclitaxel, there was no acceptable inhibitory activity against HeLa tumor, because the mice treated with the higher dose of paclitaxel died at 4 to 10 days.

These results were similar to the inhibitory effects of paclitaxel by continuous injection. However, using compound 5 it was possible to treat mice with continuous injection without side effect such as weight loss, and at the same time to obtain a better tumor regression than with paclitaxel.

Figure 2 shows the inhibitory effect of compound 5 on
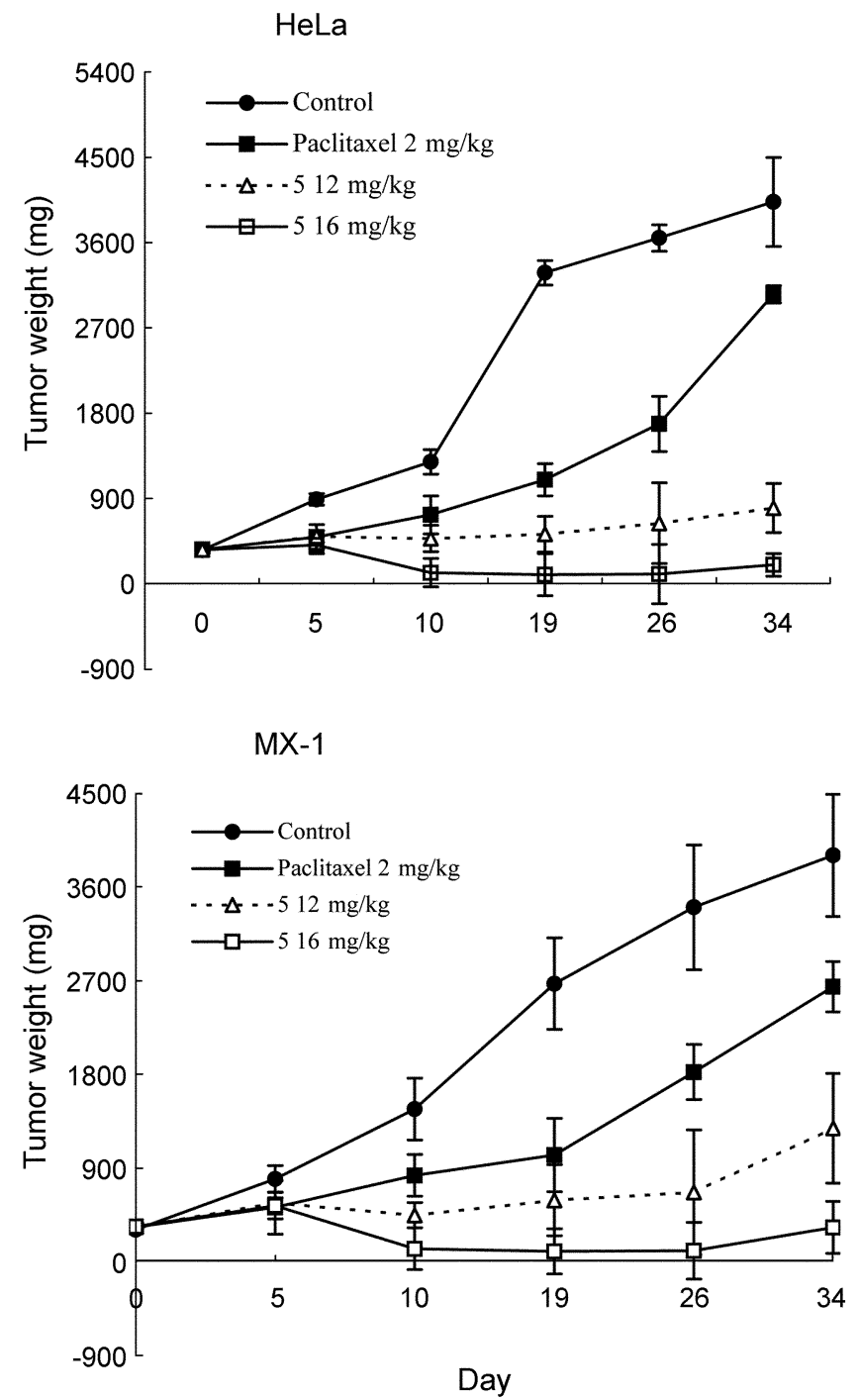

Figure 1. Anti-tumor effect of the long-term treatment of compound 5 on MX-1 and HeLa tumor implanted in Blab/c $n u / n u$ mice. The drugs were treated intravenously for daily consecutive for 15 days. The drug injection was started when tumor volume measured $100-300 \mathrm{~mm}^{3}$. Data are presented as mean $\pm \mathrm{SD}$ of tumor volume $(\mathrm{n}=10)$.

metastasis of B16 melanoma. The number of colonies identifiable on the lung surface of mice in the control group was $21.0 \pm 3.5$. The colony counts were lower in the compound 5 treated groups at both 2.5 and $5 \mathrm{mg} / \mathrm{kg}$, the established colonies being $14.4 \pm 2.3$ and $12.9 \pm 3.3$, respectively. This anti-tumor activity of compound $\mathbf{5}$ was found to be significant at both doses, compared to the paclitaxel treated group.

We have synthesized a new water-soluble paclitaxel derivative, referred to as compound $\mathbf{5}$, which has an antimetastasis activity similar to paclitaxel, but a lower toxicity than paclitaxel. In short-term chemotherapy, compound $\mathbf{5}$ was not found be effective against the human tumor cell lines, HeLa and MX-1, at the tested doses compared to paclitaxel. On the other hand, chemotherapy with compound 5 using longer-term injections produced a significant anti- 


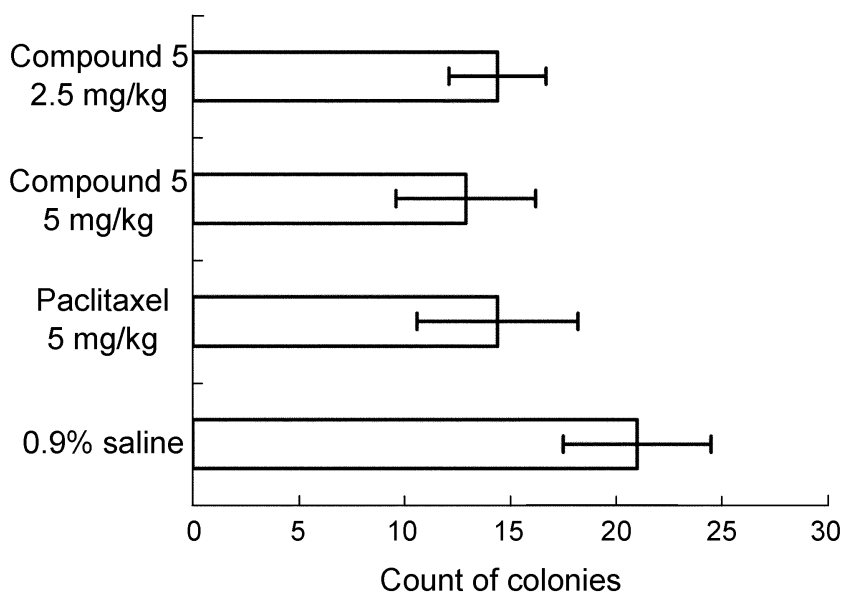

Figure 2. Anti-metastasis effect of compound $\mathbf{5}$ against murine melanoma B16F10. B16F10 cells $10^{6}$ were implanted intravenously into C57BL/6 mice (6 weeks old). The compound treatments were administered intravenously, once daily for 10 days starting on Day -2 (i.e. Day -2 to Day 7). On day 14 the mice were killed and all visible lung colonies counted.

tumor activity.

In conclusion, compound $\mathbf{5}$ was water soluble and easily formulated. In addition, employing compound $\mathbf{5}$ containing PEG of 5,000 molecular weight produced an agent that was rapidly excreted and this could be interpreted as being inactive. This response may also decrease the anti-tumor activity of the prodrug. Although compound $\mathbf{5}$ was found to have this problem, which is associated with anti-tumor activity, we nevertheless found a new therapeutic effect after long-term treatment. In addition, compound $\mathbf{5}$ exhibited a reduced toxicity, which makes it possible to increase the dose and frequency of administration for further therapeutic effectiveness. It is not clear why the high molecular PEGconjugate was associated with reduced anti-tumor activity.

Acknowledgements. We would like to thank Mr. Young-
Seok Park and Mr. Jae-Young Lee in Kolon Central Research Park for the support of intermediate synthesis.

\section{References}

1. Rowinsky, E. K.; Chaudhry, V.; Cornblath, D. R.; Donehower, R. C. J. Natl. Cancer Inst. Monogr. 1993, 15, 107.

2. Onetto, N.; Canetta, R.; Winograd, B.; Catane, R.; Dougan, M.; Grechko, J.; Burroughs, J.; Rozencweig, M. J. Natl. Cancer Inst. Monogr. 1993, 15, 131.

3. Greenwald, R. B.; Gilbert, C. W.; Pendri, A.; Conover, C. D.; Xia, J.; Martinez, A. J. Med. Chem. 1996, 39, 424-431.

4. Li, C.; Yu, D.; Inoue, T.; Yang, D.; Milas, L.; Hunter, N. M. Anticancer Drugs 1996, 7, 642.

5. Pendri, A.; Conover, C. D.; Greenwald, R. B. Anticancer Drugs Des. 1998, 13, 387.

6. Dorr, R. T. Ann. Phrmacother. 1994, $28, \mathrm{~S} 11$.

7. Goldspiel, B. R. Ann. Phrmacother. 1994, 28, S23.

8. Lorenz, W.; Riemann, H. J.; Schmal, A.; Schult, H.; Lang, S.; Ohmann, C.; Weber, D.; Kapp, B.; Luben, L.; Doenicke, A. Agents Actions 1977, 7, 63.

9. Rowinsky, E. K.; Donehower, R. C. N. Engl. J. Med. 1995, 332, 1004.

10. Weiss, R. B.; Donehover, R. C.; Wiernik, P. H.; Ohnuma, T.; Gralla, R. J.; Trump, D. L.; Barker, J. R., Jr; Vand Echo, D. A.; Von Hoff, D. D.; Leyland-Jones, B. J. Clin. Oncol. 1990, 8, 1263.

11. Riondel, J.; Jacrot, M.; Picot, F.; Bèriel, H.; Mouriquand, C.; Potier, P. Cancer Chemother. Pharmacol. 1986, 17, 137.

12. Taetle, R.; Rosen, F.; Abramson, I.; Venditti, J.; Howell, S. Cancer Trea. Re. 1987, 71, 297.

13. Shayer, D.; Bogaars, H.; Hearing, V. J.; Maizel, A.; Wanebo, H. Cancer Immunol. Immunother. 1995, 40, 277.

14. Tekol, Y. Vet. Hum. Toxicol. 1991, 33, 337.

15. Deutsch, H. M.; Glinski, J. A.; Hernandez, M.; Haugwitz, R. D.; Narayanan, V. L.; Suffness, M.; Zalkow, L. H. J. Med. Chem. 1989, 32, 788

16. Mathew, A. E.; Mejillano, M. R.; Nath, J. P.; Himes, R. H.; Stella, V. J. J. Med. Chem. 1992, 35, 145.

17. Greenwald, R. B.; Pendri, A.; Conover, C. D.; Lee, C.; Choe, Y. H.; Gilbert, C.; Martinez, A.; Xia, J.; Wu, D.; Hsue, M. Bioorg. Med. Chem. 1998, 6, 551.

18. Yamaoka, T.; Tabata, Y.; Ikada, Y. J. Pharl. Sci. 1994, 93, 601.

19. Maeda, H. Adv. Drug Delivery Rev. 1991, 6, 181. 